\title{
FLEXIÓN BIOPOLÍTICA E IMÁGENES CRÍTICAS DE LA COMUNIDAD EN LA LITERATURA RECIENTE
}

\author{
Miriam Chiani \\ Instituto de Investigaciones en Humanidades y Ciencias Sociales \\ Universidad Nacional de La Plata \\ Consejo Nacional de Investigaciones Científicas y Técnicas \\ miriamchiani@yahoo.com.ar \\ Rodrigo Montenegro \\ Centro de Letras Hispanoamericanas \\ Universidad Nacional de Mar del Plata \\ Consejo Nacional de Investigaciones Científicas y Técnicas \\ rdmontenegro@gmail.com
}

\begin{abstract}
Resumen: El presente trabajo propone a partir de una serie de intervenciones en el campo de la teoría una cartografía de propuestas artísticas desde una flexión biopolítica considerando la elaboración de imágenes críticas de la comunidad. Se abordan los textos Runa (2003) de Rodolfo Fogwill, Plop (2002) de Rafael Pinedo y En el cuerpo una voz (2018) de Maximiliano Barrientos para considerar a través de este régimen de visibilidad sus prácticas escriturarias.
\end{abstract}

Palabras clave: Biopolítica, Comunidad, Cuerpo, Violencia, Ficción.

\begin{abstract}
All through a series of interventions in the field of theory the present work intends a cartography which allow to consider a biopolitical flexion on literary writings and artistic experiments, as well an elaboration of critical images of th ecommunity. I approach the novels Runa (2003) by Rodolfo Fogwill, Plop (2002) by Rafael Pinedo and En el cuerpo una voz (2018) by Maximiliano Barrientos to consider their writing practices through this visibility regime.
\end{abstract}

Keywords: Biopolitics, Community, Body, Violence, Fiction. 
1. Existe un territorio de experimentaciones artísticas contemporáneas, que incluiría por cierto ciertas escrituras literarias, el cual pueda ser revisado desde una particular flexión biopolítica; hecho que implicaría una consideración compleja de esta construcción conceptual en la cual las artes se imbrican junto a una reflexión sobre las condiciones de vida en el presente. La composición de itinerarios críticos en clave biopolítica1 (Foucault 2001，2002，2006; Agamben 1998; Espósito 2006, 2009; Giorgi - Rodríguez 2009; Giorgi 2014; Lorey 2016) constituye un detenimiento posible para observar las modulaciones de un pensamiento que intenta recorrer, de forma privilegiada, el problema de lo viviente a fin de señalar sus escansiones, puntos neurálgicos y resistencias. Por supuesto, se hace necesario advertir la dificultad de abordaje que supone la noción de biopolítica, dado que no solamente resultan complejas las relaciones entre los conceptos de vida y política -desarrollados por la teoría desde los trabajos de Foucault-, sino que esta dificultad se encuentra en la conceptualización misma de lo viviente. Tal como sostiene Agamben, "la investigación genealógica sobre el concepto de vida" (2006, p. 31) debe afrontar el escollo, la espinosa

${ }^{1}$ Foucault (2001; 2002) emplea el concepto de biopolítica para referirse a una transformación fundamental de las sociedades modernas: el pasaje de una forma de ejercicio del poder basada en el principio de soberanía ("hacer morir o dejar vivir") a otra basada en un principio de normalización de grandes poblaciones ("hacer vivir o dejar morir"). Mientras que la primera forma es de naturaleza jurídica y se centra en la ley como instancia ordenadora del pueblo (sujeto político), la segunda se despliega en un conjunto de mecanismos de control y administración (control sanitario, de natalidad, etcétera) que produce y regula la vida de las poblaciones (sujeto biológico). Desde mediados del siglo XVIII no se trata ya del dominio del príncipe, sino de un conjunto anónimo de técnicas. A partir de entonces una serie de intervenciones como las de Agamben Esposito, Negri, Butler etc. han ampliado y problematizado los órdenes y objetos de interés o el campo de preocupaciones que supone la noción de biopolítica. 
dificultad, de su definición; el problema se imbrica con una serie de aproximaciones que se muestran provisorias a cada momento, ya sean abordadas desde la biología, la teología o la filosofía política "Pareciera que, en nuestra cultura, la vida fuese lo que no puede ser definido, pero, precisamente por esto, lo que debe ser incesantemente articulado y dividido" (2006, p. 31). Continuar este pensamiento a fin de considerar las mutaciones de aquello que merodea en la zona del bios constituye, ante todo, una observación de sus múltiples formas de división y apropiación. Por lo tanto, relevar los modos de la maquinaria de producción antropológica arrojada sobre la vida implicaría señalar las diversas formas de administración tecnocrática, política o económica sobre la materialidad de los cuerpos vivientes; habilita, asimismo, una serie de aproximaciones estratégicas que buscan conmover los principios que garantizan la estructuración de un enunciando, en apariencia inocente, como "nuestra cultura".

El corte entre lo animal y lo humano, que adoptó diversos avatares en su constitución histórica y nombró lo bárbaro, salvaje o natural para enfrentarlo contra la racionalidad civilizatoria del humanismo, configura una escansión tajante (quizás constitutiva) al interior del pensamiento occidental. Al hacer visible esa cesura para tornarla en una territorialidad difusa y móvil se habilita mecanismos perceptuales y afecciones alternativas a esa tradición de pensamiento humanista; en principio, sería posible considerarlas acciones de la biopolítica sobre la corporalidad, para luego tomar distancia desde posiciones tácticas. El animal configura una frontera móvil, un punto de indistinción entre vidas anónimas pre- 
subjetivas consideradas en el devenir de lo viviente; sostiene Agamben:

En nuestra cultura, el hombre ha sido siempre pensado como la articulación y la conjunción de un cuerpo y un alma, de un viviente y de un logos; de un elemento natural (o animal) y de un elemento sobrenatural, social o divino. Tenemos que aprender, en cambio, a pensar el hombre como lo que resulta de la desconexión de estos dos elementos y no investigar el misterio metafísico de la conjunción, sino el misterio práctico y político de la separación (2006, p. 35).

La vida, entonces, presentada como problema, como campo de tensiones siempre móviles; como inmanencia absoluta antes y después de toda filosofía de la subjetividad. Por lo cual, la vida materializada en un cuerpo y en sus figuraciones literarias adquiere una relevancia significativa en la tarea por construir un pensamiento y unas escrituras que tomen a la corporalidad como punto de apoyo para una productividad irreverente, incluso para hacer visible los dispositivos de control y violencia ejercidos sobre esa materia viviente. Afirmaba Deleuze en su último ensayo:

No habría que limitar una vida al simple momento en que la vida individual afronta la muerte universal. Una vida está en todos lados, en cada uno de los momentos que atraviesa tal o cual sujeto viviente y que miden tal o cual objeto 
vivido: vida inmanente portadora de los acontecimientos o singularidades que no hacen más que actualizarse en sujetos y objetos (2003, p. 38).

La teoría deleuzeana en torno a la vida excluye, por lo tanto, consideraciones ancladas en valencias subjetivas u objetivas para disponer en su lugar el campo abierto de multiplicidades en las cuales lo humano constituye tan solo un principio de individuación en una cadena más vasta, con lo cual el intervalo singular de una vida individual se representa como un detenimiento fortuito. Agamben recuperará esta instancia del pensamiento deleuzeano en su ensayo "¿Qué es el acto de creación?" (2016), para retomar en el centro del problema filosófico entorno a la vida su imbricación con las artes en tanto actos de resistencia. La conferencia homónima pronunciada por Deleuze en 1987 hacía derivar sus observaciones en torno a la potencia política de la acción creativa hacia sus resistencias, en vistas a "liberar una potencia de vida" (Agamben, 2016, p. 35). Resulta interesante que, ahí donde el pensamiento de Deleuze hace confluir política, arte y vida en vistas a una construcción deliberadamente refractaria a la "sociedad de control" (Deleuze, 1991; Lazzarato 2006), Agamben regresa a la filosofía aristotélica para indagar las potencias políticas a través de una "poética de la inoperosidad"2 (Agamben, 2016, p. 49), desarticulando $-\mathrm{O}$ al

2 Sostiene Agamben en su lectura de Deleuze: "el acto de creación tiene una relación constitutiva con la liberación de una potencia” (2016, p. 37). Más específicamente, el filósofo argumenta que "la potencia que el acto de creación libera debe ser una potencia interna al mismo acto, como interno a él debe ser también el acto de resistencia. Sólo de esta forma la relación entre resistencia y creación, y entre creación y potencia, se vuelven 
menos postergando-, el fundamento vitalista de la creación conceptual de Deleuze. De Foucault a Agamben y Esposito, atravesando la filosofía de Deleuze, la reflexión sobre las formas de administración de la vida intenta dar cuenta de un escenario en el cual la tecnificación, la racionalización, la inmunización configuran un paradigma molar de apropiaciones y delimitaciones sobre el cuerpo y lo viviente. Contra esas formas de dominación de los cuerpos podría señalarse como hipótesis (transitoria) de trabajo una tensión constitutiva de ciertas materias de las artes cuyo objeto es la liberación de esa potencia de vida encapsulada, la cual encuentra en el acto de creación artístico un momento privilegiado.

Esta constelación de problemas es abordada por Gabriel Giorgi (2014) en su propuesta de lectura crítica sobre la literatura latinoamericana a fin de señalar en el animal un artefacto del pensamiento, es decir, una posición que franquea la metafísica para componer un mapa de esas territorialidades políticas, cuya materia visible y sensible, siempre, se encuentra en los cuerpos. La lectura que Giorgi realiza sobre los textos de Puig y Lamborghini, entre otros, advierte sobre la relación, por

comprensibles" (2016, p. 37). El acto de creación no puede ser comprendido simplemente como un paso de la potencia la actividad, sino que se constituye en la relación entre potencia yinoperosidad, es decir, la potencia-de-no, esto es resistir el paso al acto, relación que Agamben rastrea desde Aristóteles. Sin embargo, su traspaso hacia el arte como acto de creación constituye un giro hacia la vida contemplativa, es decir, hacia una reflexividad constitutiva del pensamiento. De esta forma, "Política y arte no son tareas ni "obras" solamente: nombran, sobre todo, la dimensión en que las operaciones lingüísticas y corpóreas, materiales e inmateriales, biológicas y sociales, se desactivan y se contemplan tal cual son. [...] Y aquello que la poesía acomete con la potencia de decir, la política y la filosofía deben acometerlo con la potencia de actuar. Haciendo inoperosas las operaciones económicas y sociales, muestran qué es lo que puede un cuerpo humano, lo abren a un nuevo posible uso (2016, p. 49).

$N^{\circ} 11$. Segundo Semestre de 2019 
ejemplo, entre "animalidad y cadáver", para señalar la construcción conceptual de "modos de contestación de la violencia en contextos biopolíticos" (2014, p. 14). Es en la tensión entre "ficción, lengua y biopolítica" donde sería posible advertir una condensación de sentidos estéticos y políticos conjugados como "alternativas a la modernidad disciplinaria" (2014: 14); según Giorgi, "lo animal condensa puntos o líneas de intensidad política; funciona así como una zona privilegiada para leer líneas de intersección, núcleos temáticos y recorridos entre cultura y biopolítica" (2014, p. 14). Este mismo decurso es el elaborado por Anne Sauvagnares en su lectura de la filosofía de Deleuze, en tanto elección estratégica que permite establecer un contínum del animal al arte. La transformación, entonces, se produce en la mutación de un cambio de foco, desde la antropología a la etología, para así configurar una apuesta crítica: "Cuando los efectos de la subjetividad dejan de ser atribuidos a una esencia del hombre o a un sujeto sustancial, la separación entre naturaleza y cultura se vuelve indiferente, sin que la cuestión política del poder pierda por ello actualidad" (2006, p. 11). La lectura de Sauvagnares busca hacer pensables los caracteres posibles para un régimen de visibilidad política no-humano, que entiende de un modo específico el valor de la inmanencia en sentido deleuzeano. Ahora bien, la distancia entre el animal y el arte que se obstinan en recorrer tanto Sauvagnares como Giorgi constituye simultáneamente un territorio de experimentaciones estéticas y políticas; ahí donde concluye la palabra razonada de la política y el arte representativos (miméticos), emerge una zona de afecciones en las cuales el cuerpo viviente ocupa un 
lugar central, tanto de la reflexión crítica como del campo de artístico. En este mismo sentido, en "El animal biográfico" (2018) Julieta Yelin indaga el problema de las escrituras del yo para considerar las posibilidades teóricas de un pensamiento posthumanista; en efecto, señalar la inexistencia de biografías de animales conlleva indagar las particularidades constitutivas del bios y su solidaridad con un tipo particular de grafía. Diseñar una zona de indiscernibilidad sobre el concepto de vida se presenta, entonces, como una tarea crítica esgrimida sobre una tradición de pensamiento apoyada sobre una noción molar de sujeto, en tanto vida cualificada y protegida, cuya contra cara se encuentra en las vidas sacrificables, sin voz, sin escritura. La opción por la flexión animal constituye, en este caso, una estrategia para revisar un principio básico de la ontología occidental: la vida narrable es, siempre, una posibilidad, una escansión, que omite otras formas de vida. De modo que, tal como señala Yelin, una filosofía de tradición nietzscheana concibe como una tarea urgente realizar una indagación exhaustiva sobre "los dispositivos y modos de jerarquización y exclusión a los que es sometida la noción de vida" (2018, p. 73), porque si efectivamente no existe una biografía animal junto al espacio (posible) de una zooliteratura- indicaría un problema constitutivo a las tramas con las cuales se designa lo viviente.

Ahora bien, considerar la "dimensión biopolítica" (Quintana, 2010) de las prácticas literarias recientes, en el contexto más amplio de las artes contemporáneas, permite señalar las intervenciones de un pensamiento elaborado desde la ficción sobre la "administración y experimentación de los 
cuerpos humanos" (Quintana, 2010, p. 384) en correlación a otros cuerpos vivientes. En este sentido, los imaginarios biopolíticos en la literatura del siglo XXI habilitan una reflexión sobre nuevas formas de subjetivación, así como señalan las posibilidades de los distintos medios expresivos para involucrase en una "praxis de modos afectivos" (Zúñiga, 2008, p. 47) esgrimida contra los dispositivos biopolíticos de control. De esta forma, sería posible encontrar en las artes verbales imágenes críticas (Didi Huberman, 1997) de la comunidad, las cuales disponen modos de inteligibilidad de una pragmática de la potencia afectiva y de las fuerzas activas (Zúñiga, p. 48).La pregunta por la dimensión biopolítica en cierta zona de la literatura contemporánea es el resultado de una acción conjugada desde la filosofía, la teórica crítica y los análisis culturales; tal como sostiene Rodrigo Zúñiga, es posible advertir un "sostenido ingreso de la "vida" de los "cuerpos vivos" entre las formas del arte. Las prácticas artísticas se emplazan en un contexto en el cual "variados dispositivos [...] libran [...] nuevas alianzas y disputas por la gestión de lo viviente" (Zúñiga, p. 7). Considerar las prácticas estéticas en el contexto biopolítico implica un despliegue de estrategias sobre los cuerpos vivientes y sobre el cuerpo del arte, las cuales se implican en diversos tipos de "participación", de intervención material o de "demarcación soberana" sobre los cuerpos" (Zúñiga, p. 8). A través deestos desplazamientos categoriales podría perfilarse una idea de arte biopolítico, el cual, continuando las reflexiones de Gabriel Giorgi, entienden en esta aproximación "un umbral privilegiado de las indagaciones de la cultura" (2014, p. 17). En 
efecto, el arte biopolítico despliega un tránsito, un movimiento que va más allá de lo humano para ingresar en un territorio de exploración formal sobre las materias del cuerpo y el carácter expandido e impersonal de las experiencias sensibles; un arte que se configura a partir del desborde de los rasgos diferenciales que ordenan taxonómicamente (disciplinariamente) el mundo. En su lugar, la flexión biopolítica presenta a través de sus figuraciones y materiales un pensamiento sobre lo viviente entendido como campo de composiciones inmanentes, contigüidad que se abre para descubrir potencias impersonales poniendo en evidencia que la división humano/animal, así como todas las categorías, cesuras, divisiones y distribuciones en que se fundamenta lo humano como especie biológica son resultado de tecnologías políticas, y por tanto arbitrarias, inestables y susceptibles de modificación. Quizás, sea pertinente preguntar qué otros artefactos pueden funcionar como potenciales vectores en la redistribución de lo viviente, a fin de visibilizar una imaginación teórica posthumanista, contestataria a las distinciones entre cuerpos, sus clasificaciones y jerarquías. Desde el universo de la técnica podrían emerger otros umbrales de indistinción, por ejemplo, aquel que une lo viviente con dispositivos maquínicos; el cyborg (Haraway, 2018) funcionaría como otro artefacto de la biopolítica, indicando otras potencias, otros agenciamientos.

Las distancias y contigüidades entre el animal y el arte constituyen un territorio de significaciones al interior de una teoría que intenta registrar composiciones de afectos y regímenes de sensación; señalan un cambio visibilidad para las 
producciones estéticas al jaquear el sujeto racional de la Ilustración como agente excluyente del pensamiento crítico. En su lugar, puede componerse una modulación alternativa que pone el foco sobre las imágenes críticas de la comunidad realizadas por las artes, esgrimidas contra ese principio de individuación. La flexión biopolítica encontraría en torno a la noción de "comunidad" un concepto capital, el cual permite señalar modos diversos de producción y reflexión sobre la subjetividad, desplazando una noción de sujeto clausurado en "los confines de una pertenencia colectiva", ya que la "communitas" indica "más bien aquello que lo proyecta hacia fuera de sí mismo, de forma que lo expone al contacto, e incluso al contagio, con el otro" (Esposito, 2008, p. 16). La perspectiva biopolítica implica la activación de un vínculo entre la escritura literaria y los imaginarios culturalescomunitarios, cuyo punto de partida es la experimentación expresiva de los cuerpos junto a la precariedad de la vida, a fin de elaborar una aproximación crítica a los diversos mecanismos de ordenamiento, disciplina y violencia. Esta flexión permitiría señalar en las ficciones recientes, tal como señala Yelin, un "pensamiento del cuerpo, en los dos sentidos que admite la expresión: como cuerpo pensante y como pensamiento de lo corpóreo" (2019, p. 98). Las imágenes literarias de la comunidad, así como la indagación en los cuerpos que la componen, elaboran una trama semiótica que se presenta, no como mero escenario narrativo, sino como un territorio común que permite advertir los desplazamientos sociales, sus contactos y conflictos. 
A través de este panorama sería posible señalar una serie de escrituras en las cuales se liberan las potencias de la corporalidad y la comunidad; donde el cuerpo y el problema de aquellos sentidos pensados como comunes operan como núcleos de significación de potencias disruptivas, franqueando las fronteras de la subjetividad humanista y las construcciones solidarias a un paradigma de representaciones políticas enclavadas en el principio igualador de la racionalidad occidental. En este punto se hace evidente que existen dos modalidades, dos valencias para la flexión biopolítica, las cuales resuenan y se materializan en las creaciones del arte y la literatura. Por un lado, una crítica hacia los dispositivos de la biopolítica solidarios al paradigma modernizador y civilizatorio de occidente; por otro, frente a él, o más específicamente, contra él se extiende una "biopolítica afirmativa", que Esposito, Giorgi y Zúñiga señalan como epistemología alternativa. En este contexto, las artes establecen efectivos puntos de contacto, construyen artefactos críticos, diseñan cuerpos alternativos e imaginan una experiencia sensible refractaria al dominio humano, inmunizado, semiocapitalista (Beradi, 2016).

2. A partir del campo de indagaciones que emerge desde la teoría biopolítica, entendida en un sentido amplio, sería posible componer un itinerario de lecturas críticas en el cual advertir modulaciones y expansiones de sus problemas constitutivos. Existiría en las últimas década un tipo de literatura hecha con restos, con fragmentos de lo que alguna vez fue el arte moderno de narrar; entonces, en lugar de grandes relatos, personajes de profundidad psicológica y narraciones 
elaboradas como postulación de una Historia -la Gran Historia Novelada de América-, se elige un camino menor en el cual la épica se desgarra e insiste en instalar una lengua inmediatamente política; una lengua que, al fracturar la vocación mimética, da forma a un régimen sensible y expresivo en el cual el poder y la violencia son expuestos como potencias disruptivas al interior de cualquier consenso estético, informacional o político de las sociedades democráticas del presente. Un detenimiento posible en este itinerario señalaría una serie de textos donde el imaginario biopolítico explora modos de asociación comunitaria enfrentados a su desintegración, incluso diseñando una escritura como registro de la violencia o la ruina. Tal sería el caso de Runa (2003) de Rodolfo Fogwill y Plop (2002) de Rafael Pinedo, textos publicados con tan solo un año de diferencia por la editorial Interzona.

La novela de Fogwill elabora, a contramano de la clave hiperrealista de sus últimas novelas urbanas, una conjetura sobre la vida en comunidad aunque apelando a una imaginación casi mítica -por obliterada- en la civilización occidental, para componer en su lugar una ficción alucinada. Runa es la invención, en el relato, de una "sociedad prehistórica" (11), según describe el prólogo programático del propio autor, que intenta hacer visible lo invisible para el saber histórico. En ese sentido, la prosa de Fogwill es un regreso a ese estado indistinto donde la palabra se reduce y condensa hacia el rudimento, regresa a una figurada edad de piedra ágrafa: "Al principio: La lengua debió haber sido rudimentaria, pero pronto evolucionó. Entonces a los hombres les dieron 
nombre y esa fue la primer cagada" (2011, p. 13). Este inicio da cuenta de la hipótesis (ficcional) del texto fogwilliano: el lenguaje encarna el primer dispositivo en la elaboración de una tecnología antropológica. La lengua hace a los hombres, escribe Fogwill, anticipando las tesis de Agamben sobre la consideración del lenguaje como dispositivo privilegiado de la maquinaria biopolítica. Por lo tanto, la lengua no solo significa, no es un mero código abstracto de representación, sino una pragmática discursiva de efectos sociales, para Fogwill la lengua crea a los hombres:

Somos otros, somos los hombres hechos, los hombres escritos que se aprontan a terminar de escribir sobre el mundo los trazos caprichosos de su civilización. Casi no queda en el planeta un espacio en blanco que no hayamos estropeado con nuestras pretensiones y nuestra desmedida significación. Si lo hubiera, ya nadie sabe dónde está, de modo que no hay mejor alternativa que inventarlo (2011, p. 12).

Quizás sea posible considerar a Runa como la invención de una comunidad; ensayo que despliega una sociología conjetural para imaginar cómo la emergencia de la cultura, siempre, se realiza en la reunión de unos grupos humanos dispersos y arrojados en la intemperie. Los sesenta y dos breves textos que componen el libro indagan la necesidad de una división del saber, el poder y las ocupaciones, la aplicación de la ley, la interpretación de la naturaleza $y$, de modo programático, la función de la palabra y los relatos en el centro de esa vida 
prehistórica. La escritura rúnica de Fogwill intenta dibujar sobre las páginas de una novela contemporánea la correlación artificial entre el lenguaje, como mathesis organizativa de toda comunidad, el poder y las tecnológicas de la fabulación. Runa es, también, un ensayo sobre las modulaciones del arte de narrar, especialmente cuando se elige un registro minoritario alejado de la épica novelesca; en su lugar, el lirismo contra histórico de una comunidad imaginada insiste en recordar a la lengua como herramienta económica y marca de identidad, como principio para toda transacción, como runa -con su peso y su forma- que recuerda la artificialidad irreductible de toda herramienta humana, justamente por conjeturar una vida en estado pre civilizatorio. Toda la narración se desenvuelve en un tiempo ilusoriamente ancestral donde personajes de nombre enigmático "Oóm", Aúmm", "los sabios", discurren en una temporalidad suspendida. El dictado de las leyes a partir de la lectura de las estrellas, la vida natural, la supervivencia, la guerra, el canto en la fiesta ritual, son los temas de una novela que trabaja sobre la fractura de la noción de escritura representativa para componer una expresión condensada, una runa, que opera contra el relato de la historia. Sin embargo, el texto de Fogwill se obstina en señalar a través de ese lenguaje ultracondensado la construcción de una comunidad en la que el poder, la violencia o la literatura forman parte del mismo edificio social: "Lo que dice una canción de fiesta: Guerreros matan / buros atrapan / las viejas mienten / los buúlg saben contar" (2011: 22). Descripción poética o desvarío, deliberada creación lingüística que se ofrece como exemplum de toda arbitrariedad fraguada en el lenguaje, ya se trate de una mera transacción 
comercial, la creación de una cosmogonía, la planificación de la guerra o una teoría política sobre el Estado, el texto de Fogwill se propone hacer visible esa indistinción entre las potencias políticas de la ficción y sus efectos pragmáticos en la concreción de un entramado social; es decir, en el pacto fundacional inscripto -aunque ocluido- en toda comunidad: "Los jefes mandan y ordenan los repartos para que la fuerza de ningún hombre puede torcer la fuerza de todos y el pueblo dura aunque todos los hombres y los jefes estén muertos y vivan y manden los hijos y los nietos que hayan crecido" (2011, p. 102).

La singular escritura de Plop -cincuenta y seis breves capítulos más prólogo y epílogo- da cuenta en la forma de la distopía del más deliberado ejercicio de precisión narrativa; una ficción sobre la violencia en un escenario en el cual parece haberse desintegrado todas las garantías del humanismo, una alucinación inhumana, experiencia concentracionaria a cielo abierto. Personajes que son, apenas, las marcas de unas voces, de unos sonidos, de sus características físicas y, sobre todo, un cuerpo sometido a la precariedad. Muy lejos del realismo, la novela de Pinedo elabora una estética del deshecho y hace de la economía discursiva un pulso narrativo tan precario como la vida de sus personajes. Plop, nacido en el barro, luego violentado en una rígida estructura de poder, es obligado a sobrevivir al interior de una comunidad en la cual se ha franqueado todo resto de humanidad; de modo que desde la sumisión inicial hasta el ejercicio despiadado de la autoridad antes de su muerte, su vida se dispone como el viaje desde el margen al centro del poder: "Él era el genio de la vida en el 
barro, el artista de la supervivencia en el barro" (p. 130). En efecto, la escritura de Pinedo elabora en la ficción una teoría sobre la vida en estado de precariedad, y es en ese estado donde emerge el ejercicio descarnado del poder, la tortura o la explotación sobre los cuerpos. Tal como sostiene Claire Mercier, Plop permite advertir el esbozo de una "ecología humana" (2016), elaborando una indagación textual sobre la frontera entre lo humano y lo animal, así como el límite entre la civilización, en tanto organización comunitaria, y la violencia. En el mismo sentido, Sanchez Indart advierte en la narrativa de Pinedo la exploración de una "politicidad de los afectos, en tanto umbral de composición y disgregación de los cuerpos modelando una "experiencia de la supervivencia" más allá de las normas que definen lo humano" (2016, p. 78). La relevancia crucial de la novela se encuentra en la posibilidad de componer una escritura donde la economía en ruinas de la comunidad se traslada, por contagio, por deliberada elección, a la economía narrativa de su forma. Lejos del derroche, la escritura de Pinedo se ajusta al mismo principio de vida en estado precario que se ensaya desde la ficción, para encontrar en las afecciones del cuerpo la omnipresente necesidad de sobrevivir a partir del despliegue de un poder impiadoso. En definitiva, Plop da forma a una imagen crítica de la comunidad para mostrar explícitamente la sincronía entre poder, violencia, sexualidad y supervivencia; esa comunidad imaginada por Pinedo es la pesadilla materializada de un verdadero final de la historia, donde no hay relato, Estado o temporalidad sino un perpetuo y cíclico ejercicio de la fuerza. 
En el cuerpo una voz (2018) de Maximiliano Barrientos propone un texto al filo del delirio e instalado en ese campo de acciones donde la historia -como cualquier Historia- se hace de cuerpos y, más precisamente, de la violencia ejercida sobre ellos por un aparato político. Según Yelin, el trabajo de Barrientos sobre el lenguaje "produce una intensificación de la ambigüedad, es decir, un borramiento de la dualidad cuerpo/pensamiento, con la consecuente emergencia de cuerpos pensantes" (2019, p. 106). En ese sentido, el texto de Barrientos dispone un campo de experimentación sobre las condiciones posibles, y por momentos inquietantemente verosímiles, a las que son sometidos los cuerpos vivientes cuando se desfondan todos los marcos de la vida pensada como bien común en un proyecto civilizatorio y, en su lugar, se instala la guerra, la violencia y la atrocidad.

El relato se inicia con el impulso de una road movie. Dos hermanos escapan en un auto, atraviesan parajes desolados, uno de ellos está herido de bala, buscan atención médica, negocian para conseguir una intervención quirúrgica clandestina, para luego continuar el escape hacia la selva hasta refugiarse en el fuselaje de un avión, restos en medio del monte. Ese primer movimiento no permite ver, ni siquiera especular, con el devenir de la novela, la cual se convierte en una visión en la cual el Estado Plurinacional de Bolivia se ha desintegrado cediendo a los impulsos del nacionalismo Camba. En este punto, la narración de Barrientos se proyecta como un relato anticipatorio de un horror posible, que sin embargo se sitúa en el centro de la racionalidad globalizada contemporánea. Barrientos recuerda que todo "orden" es el 
resultado de un "colapso", aún (o sobre todo) la pax de las sociedades democráticas; insiste en afirmar que sobre el manto de los consensos políticos que administran la vida se encubren y solapan pulsiones de aniquilamiento. $\mathrm{Y}$ en efecto, la escritura de Barrientos puede ser pensada como la construcción de una poética de la violencia en la proyección de una visión política distópica. Una mirada o una conjetura hacia un futuro posible y amenazador en el cual los cuerpos serán atravesados por la guerra y el sometimiento. En este preciso sentido, la novela es tanto un ensayo sobre la vida desnuda de las víctimas del pasado sobre las cuales se erigieron los Estados Nacionales, como una ensoñación en clave de pesadilla sobre las víctimas futuras.

Una vez que se abandona el impulso del relato de ruta, de escape, de supervivencia, el texto de Barrientos se dedica a desplegar una minuciosa carnicería. Al modo de los Tadeys lamborghinianos la novela repite las mil y un caras del sadismo: desde el canibalismo a la tortura, desde la violación al despellejamiento. Matanzas llevadas a cabo en el tiempo muerto de un colapso - de un estado de excepción- por parte de brigadas paramilitares, cuyo insigne protagonista, el General, adquiere el perfil del criminal de guerra quien debe afrontar el costo de sus prácticas.

El segundo movimiento del texto es fracturar el tiempo, dejarlo fluir, para advertir las consecuencias de ese nuevo orden esparcido sobre lo que alguna vez fue Bolivia. El protagonista, ahora, se ha convertido en un agente del Estado dedicado a la recopilación de testimonios para los servicios de inteligencia. Aparece, entonces, en el interior de la ficción, la 
modalidad del testimonio como un gesto ritualizado a partir del cual la voz de la víctima se convierte en un bien común, en un resto de la violencia perpetuada en la memoria colectiva. El testimonio, sugiere la narración de Barrientos, es el lugar social -aún en el marco de la ficción- en el cual la voz se une plenamente al cuerpo y a su memoria para proyectarse hacia los otros, es decir, hacia el afuera. Los cuerpos que hablan tienen nombres, edades, ocupaciones, pero poco importan; el testimonio los hace parte de una tragedia común, de un destino o historia, de un padecimiento colectivo. Pero, sobre todo, la inscripción del testimonio recuerda, junto al título, el modo extrañado de nombrar a ese viviente que habla, al ser parlante que pese a poseer la capacidad única de construcción simbólica -de una lengua, de un Estado, de una comunidad-arrastra un componente caníbal, una pulsión de muerte que aniquilando a otros no cesa de comunicar el fracaso del proyecto llamado "humanidad", o quizás en clave filosófica, "humanismo". Aun así, el texto de Barrientos no se deja clasificar en una mera transcripción de voces testimoniantes; se mueve hacia un territorio difuso en el cual breves entradas de escritura formulan intensos capítulos que caben en una página. En esa zona, la novela de Barrientos se contrae; deja de lado la oralidad para ingresar en una prosa ajustada, por momentos lírica, que construye imágenes antes que relato; para luego encausarse en el ritmo narrativo de la venganza y preguntar: ¿cuál es el destino de los criminales de guerra, existe una justicia que no se revele, en el final, como un ejercicio de violencia, es decir, como retribución? 
Finalmente, en el interior de la ficción distópica de Barrientos se aloja uno de los problemas fundamentales que recorre la realidad política globalizada, esto es, señalar el límite lábil entre las reivindicaciones autonomistas -ya sea en Sudamérica o en Europa- y los nacionalismos, para luego avanzar un poco más, y conjeturar la solidaridad entre los proyectos nacionalistas y el racismo o la segregación cultural. La imaginación política de la ficción elaborada por En el cuerpo una voz subraya la posibilidad real de un resquebrajamiento de las condiciones de la existencia en el presente, ya sea por el giro conservador de esas reivindicaciones identitarias, ya sea como advertencia. Contra el Gran relato de la Historia como proyecto lanzado hacia el futuro, cuyo origen se encuentra en la filosofía de la Ilustración, con su confianza en la racionalidad exacerbada hasta el cientificismo positivista, el cual leía la marcha inexorable del tiempo hacia el progreso de la humanidad, Barrientos inserta su voz disidente: no hay garantías de que el futuro se transforme en la peor pesadilla del pasado. Para realizar esta advertencia el experimento narrativo se conjuga sobre una constelación de significantes que parecen obliterados en el panorama de cierta literatura actual obsesionada por la intimidad y el subjetivismo: Estado, nación, historia, violencia. Barrientos trabaja sobre ellos, aunque no para restaurar un estadio conservador de cariz decimonónico, sino para demostrar la productividad de la imaginación política, cuando se entiende que no existen canales privilegiados para ensayar preguntas y respuestas sobre los modos en que la administración de la vida disciplina a los cuerpos. Su voz, entonces, es el resto de una identidad, una 
mínima resistencia facetada, disgregada en el cuerpo social y en el cuerpo literario; una palabra que señala las posibilidades latentes de repetir la historia, no como tragedia, ni como farsa, sino como sacrificio biopolítico.

\section{3. (Coda, mínima)}

Las novelas de Fogwill, Pinedo y Barrientos podrían expandirse hacia una serie crítica de textos y experimentaciones artísticas -pienso en Campo minado (2017) de Lola Arias y Diarios del odio (2017) de Roberto Jacoby y Syd Krochmalny- en vistas a hacer visibles las relaciones que las artes establecen en el presente con las nociones de Estado, historia y violencia, elaborando transposiciones enfocadas sobre la materia expresiva de los cuerpos, el registro de la memoria o las diversas tecnologías de disciplinamiento -desde la guerra a la violencia microfísica-. A partir de estas acciones sería posible revisar las condiciones de emergencia y realización de una comunidad, conjeturadas desde los materiales estéticos en un régimen "no catastrófico" de producción e imaginación teórica, tal como describe García Canclini (2010). Este itinerario crítico procuraría leer las diversas revisiones y desplazamientos que la ficción esgrime contra las formas de dominación del paradigma biopolítico inmunitario; es decir, una reflexión sobre el bios en el estado actual del capitalismo realizada a través de un campo de exploraciones formales, esto es, estéticas, involucradas en la creación de nuevas formas de vida, de asociación, donde el 
problema de la communitas permite considerar el diseño de epistemologías críticas o alternativas.

\section{Referencias Bibliográficas}

Agamben, G. (2016) [2006]. Lo abierto, el hombre y el animal. Buenos Aires: Adriana Hidalgo editora.

(2016). “¿Qué es el acto de creación?” en El fuego y el relato. Madrid: Sexto Piso.

Barrientos, M. (2018). En el cuerpo una voz. Buenos Aires: Eterna Cadencia editora.

BeradiBifo, F. (2016). Generación post alfa [2007]. Buenos Aires: Tinta Limón.

Deleuze, G.; Guattari, F. (2006). Mil mesetas. Valencia: PreTextos.

Barcelona: Anagrama.

(2009) [1991]. ¿Qué es la filosofía?

Deleuze, G. (1991). Posdata sobre las sociedades de control. Christian Ferrer (Comp.) El lenguaje literario, $t .2$. Montevideo: Ed. Nordan.

Didi-Huberman, G. (1997). Lo que vemos, lo que nos mira. Buenos Aires: Manantial

Esposito, R. (2006). Bios. Biopolítica y filosofía. Buenos Aires: Amorrutu

(2009). Comunidad, inmunidad y biopolítica. Barcelona: Herder.

Fogwill, R. (2011) [2003]. Runa. Buenos Aires: Interzona. 
Foucault, M. (2001). Defender la sociedad. Curso en el Collage de France (1975-1976). Buenos Aires: F.C.E. (2002). Historia de la sexualidad. La voluntad de saber. Buenos Aires: Siglo XXI Editores. (2006). Seguridad, territorio y población. Curso en el Collage de France (1977-1978). Buenos Aires: F.C.E.

García, L. (2016). "Prólogo" Cuadernos del GESCAL. Revista del Grupo de Estudios sobre Colombia y América Latina. Año 3, Núm 1. Buenos Aires, versión Impresa, 17-21.

García Canclini, N. (2010). La sociedad sin relato. Antropología y estética de la inminencia. México: Katz Editores.

Giorgi, G. (2014). Formas comunes. Ciudad Autónoma de Buenos Aires: Eterna Cadencia editora.

Giorgi, G. y Rodríguez, F. (2009). Ensayos sobre biopolítica. Excesos de vida. Buenos Aires: Paidós.

Haraway, D. (2018). Manifiesto para cyborgs: ciencia, tecnología y feminismo socialismo a finales del siglo $X X$. Mar del Plata: Letra Sudaca Ediciones.

Lazzarato, M. (2006). Por una política menor. Acontecimiento y política en las sociedades de control. Madrid: Traficantes de sueños.

Lorey, I. (2016). Estado de inseguridad. Gobernar la precariedad. Madrid: Traficantes de sueños.

Mercier, C. (2016). "Ecología humana en la trilogía de Rafael Pinedo: Plop, Frío y Subte" Estudios de Teoría Literaria, año 5, núm. 10, 131-143.

Pinedo, R. (2012) [2002]. Plop. Buenos Aires: Interzona.

Quintana, I. (2010). "Imágenes y sueños de la ciudad futura (literatura y cine): Biopolítica y ciencia ficción”. Orbis Tertius, 15 (16). En Memoria Académica. 
(2012). "Ficciones de lo (in)humano: biopolítica, ciencia-ficción y fantástico". Revista Iberoamericana, Vol. LXXVIII, Núms. 238-239, 367-387.

Rancière, J. (2009). El reparto de lo sensible. Santiago de Chile: LOM Ediciones.

Sauvagnargues, A. (2006) Deleuze: del animal al arte. Buenos Aires: Amorrutu.

SanchezIndart, C (2016) "Restos de vida. Estéticas de la supervivencia y políticas afectivas de lo común en Rafael Pinedo y Carlos Ríos”. $452^{\circ} \mathrm{F}$ : revista de teoría de la literatura y literatura comparada, Universitat de Barcelona, $14,69-86$.

Yelin, J. (2019). "La voz de nadie. Sobre el pensamiento del cuerpo en la literatura latinoamericana reciente" en Pasavento. Revista de Estudios Hispánicos, vol. VII, núm. 1, 97-113.

Zúñiga, R. (2008) La demarcación de los cuerpos. Textos sobre arte y biopolítica. Santiago de Chile: Ediciones Metales Pesados. 